Check for updates

Cite this: RSC Adv., 2018, 8, 36647

\title{
The first morphologically controlled synthesis of a nanocomposite of graphene oxide with cobalt tin oxide nanoparticles
}

\author{
Saba Jamil, ${ }^{a}$ Hasnaat Ahmad, ${ }^{a}$ Shafiq-ur-Rehman, ${ }^{a}$ Shanza Rauf Khan ${ }^{a}$ \\ and Muhammad Ramzan Saeed Ashraf Janjua (D)*bcd
}

In the present research, the degradation and decolorization of Reactive Black 5 synthetic dye at 30 ppm concentration under sun irradiation in the presence of a newly synthesized graphene based cobalt tin oxide nanocomposite were investigated. These nanoparticles were synthesized by a simple hydrothermal approach using precursor chloride salt i.e., stannous chloride and cobalt chloride and then adsorbed on the surface of RGO by a solvothermal process by changing the condition. The newly synthesized product was subjected to various instrumentation to study the morphology and other properties. X-ray powder diffraction analysis (XRD) explained the structural composition and various parameters of the product, which were further verified by Vesta software. The surface morphology of the product was analyzed by scanning electron microscopy (SEM) and it was observed that the size of each cube was approximately 5-10 $\mu \mathrm{m}$ from every face of the cube. Transmission electron microscopy (TEM) explained that the nanoparticles were within the range of 100-250 nm. These synthesized nanocubes were used in one more application, which was the investigation of the fuel efficiency in the presence of different concentrations of newly synthesized nanocomposites as a catalyst. The efficiency of kerosene oil was investigated by studying different parameters: the flash point, fire point, specific gravity, cloud point, pour point, and calorific value at increasing dosages of catalyst (0,30,60 and 90 ppm). It was observed that the values of these parameters changed significantly by changing the concentration of the catalyst dosage. The effect of the nanoparticles on the degradation of the RB 5 azo dye showed the highest removal percentage at the largest value of catalyst dosage, which was $0.70 \mathrm{mg} \mathrm{ml}^{-1}$ with the highest value of $3 \mathrm{ml}$ of hydrogen peroxide.

Received 12th July 2018

Accepted 9th October 2018

DOI: $10.1039 / \mathrm{c} 8 \mathrm{ra05962d}$

rsc.li/rsc-advances based photocatalysts and their derivatives have been used for the degradation of (BPA) in contaminated industrial wastewater. ${ }^{7}$ The controlled morphological synthesis of single metal oxides at the nano and micro level by using a hydrothermal bottom-up approach has become a promising method of synthesis. ${ }^{8}$ The many physical and chemical properties of metal oxide nanoparticles depend on the aspect ratio, crystalline density and stacking number. ${ }^{9}$ In the case of simple $\mathrm{SnO}_{2}$ nanoparticles, they have been widely used as electrocatalysts, ${ }^{\mathbf{1 0}}$ photocatalysts ${ }^{\mathbf{1 1}}$ and fuel additives. ${ }^{12}$ Similarly, cobalt oxide nanoparticles have been used in the electrochemical detection of hydrogen peroxide, ${ }^{13}$ gas sensing ${ }^{14}$ and aerobic oxidation of alcohol in the liquid phase. ${ }^{\mathbf{1 5}}$ On the basis of these unique properties and the applications of these two metals, many researchers have attempted to achieve a good controlled morphology of CoSn oxide or hydroxide nanoparticles by different methods i.e., by electrostatic spray deposition (ESD), ${ }^{\mathbf{1 6}}$ a wet sonochemical method ${ }^{17}$ and a hydrothermal approach. ${ }^{18} \mathrm{~A}$ catalyst with nonporous oxygen evolution was prepared by selective electrochemical etching of cobalt hydroxystannate nanoparticles and applied in the oxygen evolution reaction 
(OER) because of its unique properties of high surface area and high compatibility, when $\operatorname{CoSn}(\mathrm{OH})_{6}$ nanoparticles were calcined at $400{ }^{\circ} \mathrm{C}$, they changed into cobalt tin oxide. ${ }^{19-21}$

Chemically synthesized graphene oxide (GO) is an atomically fine sheet of graphite powder that can be used as a precursor for graphene sheets with its own properties. ${ }^{22}$ GO has excellent properties that make it an interesting material in advanced future applications in the fields of electronics and photonics, ${ }^{23}$ solar cells ${ }^{24}$ and wireless humidity sensing. ${ }^{25}$ In addition, many dyes are visible in water at concentrations as low as $1 \mathrm{ppm}$, which is enough to present an aesthetic problem. ${ }^{26}$ Many research papers are also available in the scientific literature in which bimetallic nanoparticles have been prepared by different methods ${ }^{27-31}$ and on the basis of their different applications have been reported. ${ }^{32,33}$ Many scientists have reported graphene based composites with oxides such as $\mathrm{BiFeO}_{3}$, composites with RGO, ${ }^{34} \mathrm{CeO}_{2}$ /graphene nanocomposites ${ }^{35}$ and $\mathrm{TiO}_{2}$ composites with graphene nanosheets ${ }^{36}$ but a composite of tin cobalt oxide nanoparticles with graphene oxide for the application of RB 5 dye degradation and as a fuel additive has not been reported earlier, although some scientists have reported this composite with different applications..$^{32,33,37,38-43}$ The present research has filled this gap in the literature as a $\mathrm{C}_{16} \mathrm{Co}_{4} \mathrm{O}_{16} \mathrm{Sn}$ nanocomposite with RGO is reported here with the unique applications of the photocatalytic degradation of the RB 5 azo dye and the investigation of the effect of this newly synthesized nanocomposite on the efficiency of kerosene oil. Azo reactive dyes that contain one to four azo groups in their chemical structure represent one main group of textile dyes, usually attached with two radicals, exceptionally one, but usually both, are aromatic groups. These dyes are chemically stable and difficult to degrade. ${ }^{44}$ The RB 5 dye was removed by the Fenton's oxidation (FO) process by using a significant amount of $\mathrm{FeSO}_{4}$ and hydrogen peroxide. ${ }^{45}$ This dye was also investigated in heterogeneous aqueous solutions which contain semiconductor oxides i.e., $\mathrm{CO}_{2}, \mathrm{NO}_{3}{ }^{-}$, and $\mathrm{SO}_{4}{ }^{2-}$ ions as photocatalysts. ${ }^{46} \mathrm{~A}$ UV reactor with $\mathrm{TiO}_{2}$ was used to break down the color of RB 5 as an annular photoreactor. ${ }^{47}$ Doped $\mathrm{TiO}_{2}$ in the presence of $\mathrm{N}$ and $\mathrm{F}$ increases the intrinsic properties of the catalyst and shows an increased kinetic UV photoreactivity as compared to the un doped $\mathrm{TiO}_{2}$ in the degradation of 1,3,5-triazine herbicides. ${ }^{48}$ Cao et al. reported the synthesis of a graphene- $\mathrm{TiO}_{2}$ composite and its application for tetrabromobisphenol A degradation. ${ }^{49}$ Karthik et al. used a graphene-cerium molybdate composite for the photocatalytic degradation of the antibiotic chloramphenicol. ${ }^{50}$ Al-Nafiey et al. used a graphene-cobalt oxide composite for the removal of three organic dyes (rhodamine $\mathrm{B}$, methyl orange and rose bengal). ${ }^{51}$

The discharge of industrial wastewater containing dye pollutants presents acute or long term toxicity on ecosystems. ${ }^{4,52}$ It is estimated that annually 80000 tons of more than ten thousand various kinds of dyes are synthesized worldwide and approximately $5.0-10.0 \%$ are assimilated into wastewater bodies by many procedures. $.^{53} 10-15 \%$ of all reactive industrial dyestuffs are excreted directly into wastewater due to inefficiency in dyeing operations. ${ }^{54}$ Thus, the removal of reactive dyes is a serious challenge. ${ }^{55}$ This is why the RB 5 azo dye was used as a model to examine the catalytic properties of the newly synthesized nanocomposite.

\section{Materials and method}

$\mathrm{SnCl}_{4} \cdot 5 \mathrm{H}_{2} \mathrm{O}, \mathrm{CoCl}_{2} \cdot 6 \mathrm{H}_{2} \mathrm{O}$ and pallets of sodium hydroxide $(\mathrm{NaOH})$ were used for the synthesis of nanocubes. Graphite powder, potassium permanganate $\left(\mathrm{KMnO}_{4}\right)$, sodium nitrate $\left(\mathrm{NaNO}_{3}\right)$, sulfuric acid $\left(\mathrm{H}_{2} \mathrm{SO}_{4} 98 \%\right)$, and hydrogen peroxide $\left(\mathrm{H}_{2} \mathrm{O}_{2}\right)$ were used for the synthesis of graphene oxide. Ethylene glycol was used for the synthesis of the nanocomposite. All chemicals were analytical grade and used without further purification. Deionized water was used throughout the experimental work.

\section{Synthesis of nanoparticles}

Cobalt tin oxide nanoparticles were synthesized by a simple hydrothermal technique. In a typical approach, $0.3 \mathrm{~g}\left(\mathrm{SnCl}_{4}{ }^{-}\right.$ $\left.\cdot 5 \mathrm{H}_{2} \mathrm{O}\right)$ and $0.6 \mathrm{~g}\left(\mathrm{CoCl}_{2} \cdot 6 \mathrm{H}_{2} \mathrm{O}\right)$ with an atomic ratio of $1: 2$ were mixed in $30 \mathrm{ml}$ of deionized water under constant magnetic stirring for 30 minutes at $500 \mathrm{rpm}$. After sometime they were completely dissolved. Then $7 \mathrm{ml}$ of a $4 \mathrm{~mol} \mathrm{~L}^{-1} \mathrm{NaOH}$ solution was added slowly into the solution. For further purification, the solution was treated in a Teflon lined stainless steel hydrothermal reactor autoclave and the temperature was maintained at $200{ }^{\circ} \mathrm{C}$ for 5 hours. After 5 hours, the hydrothermal autoclave reactor was allowed to naturally cool to room temperature for several hours. The precipitates of the product were collected by the process of centrifuging and were washed with ethanol and distilled water. The obtained product was dried in an oven at $60{ }^{\circ} \mathrm{C}$ for 24 hours as reported in a previous research paper. ${ }^{56}$

\section{Synthesis of graphene oxide (GO)}

GO was synthesized by taking $90 \mathrm{ml}$ of $99 \%$ pure $\mathrm{H}_{2} \mathrm{SO}_{4}$ and $2.1 \mathrm{~g}$ of $98 \% \mathrm{H}_{3} \mathrm{PO}_{4}$ and stirring for one hour. After one hour of stirring at $500 \mathrm{rpm}, 2 \mathrm{~g}$ of graphite flakes was added to the solution in a $500 \mathrm{ml}$ volumetric flask in an ice bath and the temperature was maintained at $0-5{ }^{\circ} \mathrm{C}$ for two hours. $15 \mathrm{~g}$ of $\mathrm{KMnO}_{4}$ powder was slowly added into the suspension during the next three hours of stirring at $500 \mathrm{rpm}$ and the temperature was maintained at $15-20{ }^{\circ} \mathrm{C}$. After 6 hours, $184 \mathrm{ml} \mathrm{H}_{2} \mathrm{O}$ was carefully added into the solution under constant stirring and the temperature was maintained at $60-70{ }^{\circ} \mathrm{C}$. After completing 8 hours of stirring at $500 \mathrm{rpm}$, the solution passed into the reflux system for 20-25 minutes at $100{ }^{\circ} \mathrm{C}$ temperature. After refluxing, the solution was cooled down to $30^{\circ} \mathrm{C}$ and this temperature was maintained for 4 hours and then $40 \mathrm{ml}$ of hydrogen peroxide was added into the solution. The color of the solution quickly changed and the bubbles of the suspension from the flask was noted. In the last step, the solution was divided into three beakers and then $150 \mathrm{ml}$ of water was added into each beaker and they were left overnight. The $\mathrm{pH}$ of the solution was maintained by a process of centrifuging several times. The solution was placed in an oven at $60{ }^{\circ} \mathrm{C}$ and the product was dried and used for further analysis. 


\section{Synthesis of the nanocomposite}

The tin cobalt oxide based nanocomposite was synthesized by a simple solvothermal method by changing the solvents and conditions of the reaction and the results of these variations are discussed in Experimental section. In the end, the conditions and solvent that gave the best result were determined. Typically in this method, $60 \mathrm{ml}$ of ethylene glycol was added as the solvent into which $0.15 \mathrm{~g}$ of graphene oxide was mixed during 40 minutes of stirring on magnetic plates at $500 \mathrm{rpm}$. After mixing graphene oxide into the solvent, $0.31 \mathrm{~g}$ of tin cobalt oxide was slowly added into the solution and stirred again for one hour. After stirring for one hour, the solution was placed in a Teflon lined stainless steel autoclave for 4 hours at $200{ }^{\circ} \mathrm{C}$ for further purification. After passing this 4 hour time period, the autoclave was placed at room temperature and the solution was cooled down naturally. The precipitate of the solution was collected by the process of centrifugation several times. The product was dried in the oven at $60{ }^{\circ} \mathrm{C}$ overnight. The dried product was placed in the electric furnace for calcination at $400{ }^{\circ} \mathrm{C}$ for 5 hours.

\section{Characterization}

Powder XRD patterns of the nanoparticles were obtained from a Rigaku D/max Ultima III X-ray diffractometer with a radiation source of Cu-K $\alpha$ (wavelength $=1.54174 \AA$ ) at $45 \mathrm{kV}$ and $60 \mathrm{~mA}$ at a scanning step size of $0.020^{\circ}$ in the $2 \theta$ range $10.015-80.012^{\circ}$. The XRD results were analyzed with the help of MATCH 3 software and the lattice parameters were calculated. The structural model was constructed on VESTA software. Scanning electron microscopic calculations were performed at 250 Quanta with a pressure of $70(\mathrm{~Pa})$ and $30 \mathrm{kV}$ power. The patterns showed the cubic crystal structure of these nanoparticles. The catalytic reduction and absorption spectrum of the synthetic dye RB 5 was examined by a Halo DB 20 double beam spectrophotometer with the wavelength range of 400-700 $\mathrm{nm}$. Investigation of the fuel properties by adding the newly synthesized graphene based tin cobalt oxide nanocomposite into the fuel to check the effect on the fuel efficiency was carried out in which the flash and fire point was monitored by the APEXJCX309 Closed Cup Flash Point Tester. An APEX-JCX406 oxygen bomb calorimeter was used to calculate the calorific value of the fuel. Specific gravity values were calculated by the gravity meter DA- 640 .

\section{Result and discussion}

\section{EDX analysis}

Energy Dispersive X-ray (EDX) analysis of the synthesized nanocomposite elements is shown in Fig. 1. The EDX spectrum describes the presence of Co, oxygen, tin and carbon atoms in the newly synthesized $\mathrm{C}_{16} \mathrm{Co}_{4} \mathrm{O}_{16} \mathrm{Sn}$ nanocomposite. It can be seen from Table 1 that the atom percentage of Co is more than half of all the elements present in the nanocomposite.

\section{XRD results of graphene oxide and the composite}

Fig. 2(a) shows the XRD pattern of GO in the 2-theta range $10-80^{\circ}$. One sharp diffraction peak at $12.521^{\circ}$ with the (001) $h k l$ plane is

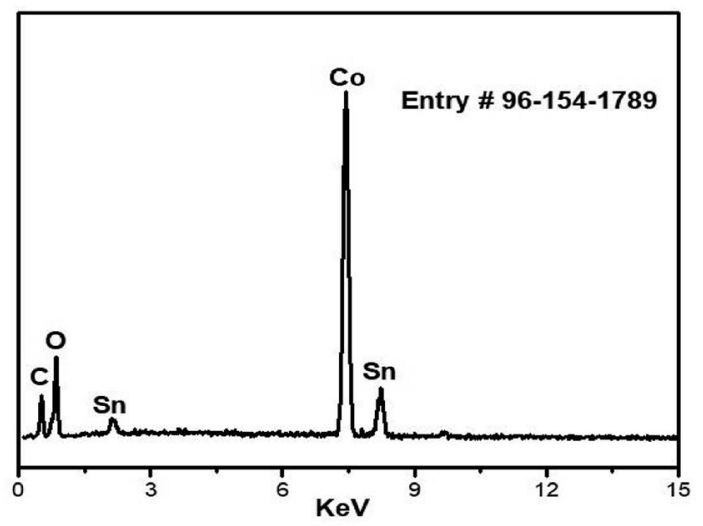

Fig. 1 EDX pattern of the newly synthesized $\mathrm{C}_{16} \mathrm{CO}_{4} \mathrm{O}_{16} \mathrm{Sn}$ nanocomposite.

Table 1 EDX elemental microanalysis (atom\%) of the $\mathrm{C}_{16} \mathrm{CO}_{4} \mathrm{O}_{16} \mathrm{Sn}$ nanocomposite sample

\begin{tabular}{lllll}
\hline Sample & Co (\%) & Sn (\%) & O (\%) & C (\%) \\
\hline $\begin{array}{l}\text { GO based cobalt tin } \\
\text { oxide nanocomposite }\end{array}$ & 54.55 & 14.45 & 16.63 & 14.27
\end{tabular}

observed. This diffraction peak is characteristic of GO (JCPDS 96810-0415). GO typically contains some functional groups $(\mathrm{OH}$, -COOH etc.) along with water molecules. During reduction, GO loses water molecules upon treatment in a furnace at high temperature or sometimes gets fully rid of functional groups by heating at more than $1000{ }^{\circ} \mathrm{C}$. In Fig. 2(b), the X-ray diffraction pattern of $\mathrm{C}_{16} \mathrm{Co}_{4} \mathrm{O}_{16} \mathrm{Sn}$ can be seen. The XRD pattern of cobalt tin oxide nanoparticles is discussed in a previous article. ${ }^{56}$ In Fig. 2(b), straight sharp diffraction peaks explain that the product is pure and well crystallized. Strong and sharp diffraction peaks at the 2theta values $15.621^{\circ}, 17.541^{\circ}, 25.453^{\circ}, 28.504^{\circ}, 30.744^{\circ}, 33.241^{\circ}$, $36.203^{\circ}, 45.443^{\circ}, 53.191^{\circ}, 63.961^{\circ}, 73.513^{\circ}$ and $75.793^{\circ}$, which are associated with $h k l$ planes (311), (222), (242), (513), (060), (444), (571), (682), (793), (868) and (797), respectively, can be seen. These sharp diffraction peaks are characteristic of the newly synthesized GO based tin cobalt oxide nanocomposite $\left(\mathrm{C}_{16} \mathrm{Co}_{4} \mathrm{O}_{16} \mathrm{Sn}\right.$, JCPDS no 96-900-7767). The product investigation report, in which crystal parameters, cell parameters, space groups, atomic coordinates, lattice parameters, bond lengths, bond angels, volume, density, and $d$-spacing are shown in Table 2 .

Detailed study of the diffraction peaks illustrates that the synthesized $\mathrm{C}_{16} \mathrm{Co}_{4} \mathrm{O}_{16} \mathrm{Sn}$ nanocomposite possesses a cubic lattice structure with a space group of $F-43 c$. Fig. 3(a) shows that the Sn atoms are located at the corner of the cube while Fig. 3(b) shows that the cobalt atoms which are represented with a blue color are present at the center of the walls of the cube and Fig. 3(c-d) describes the presence of oxygen atoms in the center of the cube. The positions of all the atoms of the product are shown in Fig. 3(e). The positions and arrangement of all the atoms over the carbon atoms can be seen in Fig. 3(f). The three dimensional cubic lattice with the placement of all atoms is described in Fig. 3(g). 

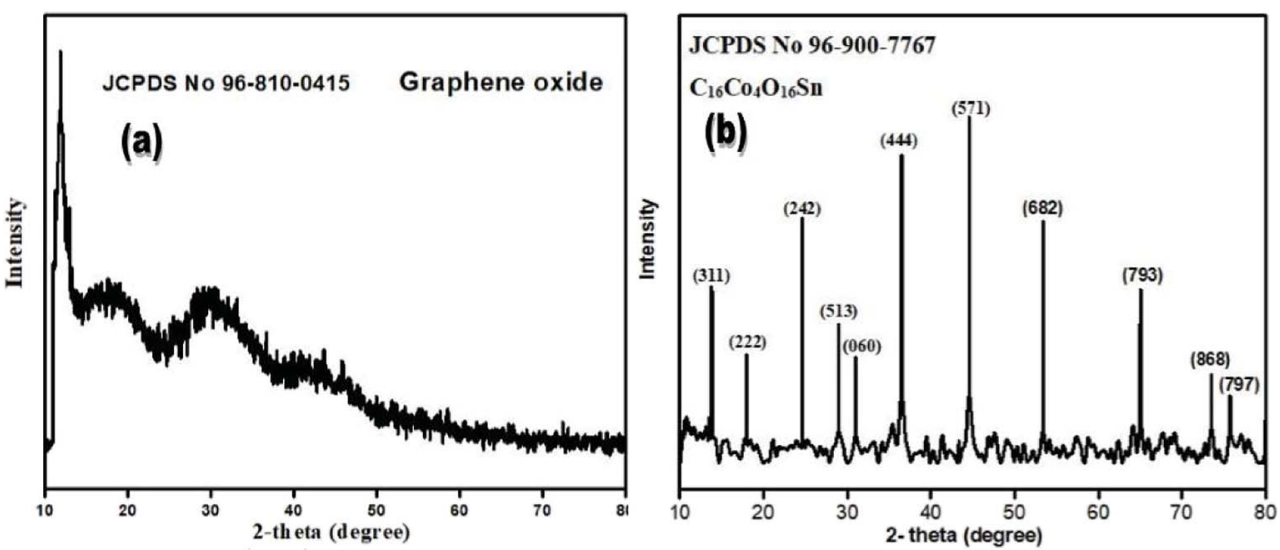

Fig. 2 (a) XRD pattern of $\mathrm{GO}$ and (b) the newly synthesized $\mathrm{C}_{16} \mathrm{Co}_{4} \mathrm{O}_{16} \mathrm{Sn}$ nanocomposite.

\section{SEM and TEM analysis of the nanoparticles}

SEM and TEM images of the tin cobalt oxide nanoparticles are given in Fig. 4(a) and (b), respectively. In Fig. 4(a), the SEM image of the simple tin cobalt oxide nanoparticles with a magnification of $5000 \times$ can be seen. A number of small cubes are visible in this image. Similarly, the TEM image of the simple tin cobalt oxide at a magnification of $50000 \times$ can be seen in Fig. 4(b). The size of these particles lies in the 70-200 $\mathrm{nm}$ range.

\section{SEM analysis of the nanocomposite}

In Fig. 5(a) and (b), the 30 micro meter range with $1600 \times$ and $1579 \times$ magnification at a 250 quanta clean surface can be seen. In Fig. 5(c) and (d), in a 5 micro meter range with a high magnification of $6000 \times$, small rough nano surfaces can be seen but no small cubic nanoparticles are seen, which is why with some modifications in the technique, clear and smooth SEM images of the synthesized $\mathrm{C}_{16} \mathrm{Co}_{4} \mathrm{O}_{16} \mathrm{Sn}$ nanocomposite at different magnifications are shown in Fig. 6(a-d).

In Fig. 6(a), with a 20 micro meter range and a $2000 \times$ magnification at 250 quanta, small nanoparticles can be seen. The blue arrows indicate the surface of GO on which the newly synthesized cobalt tin oxide nanoparticles are adsorbed. In Fig. 6(b) and (c), the 10 micro meter view of the cube shape nanoparticles with the same magnification of $4000 \times$ but with a different value of high voltage i.e., $12.50 \mathrm{kV}$ and $20.00 \mathrm{kV}$, respectively, can be seen. This view also shows that all the synthesized nanoparticles are separate from each other with the perfect corner edges of the cubes. In Fig. 6(d), the smooth and clear surface of the cubes of the nanoparticles at a 5 micro meter range with a $8000 \times$ magnification at 250 quanta can be seen. All the SEM images are captured in the presence of a gold coating at 250 quanta because at high magnification, the cobalt and tin metal shows charge in the presence of reduced graphene oxide (RGO). These highly magnified images show that the product comprises of compact cubes of tin cobalt hydroxide over the surface of RGO.

\section{TEM analysis of the nanocomposite}

To explore the morphology of the newly synthesized GO based bimetallic oxide nanocomposite in more detail at the nanoscale,
TEM images at different magnifications are shown in Fig. 7(a-d). It can be clearly observed from the images of Fig. 7(a) that, at $250 \mathrm{~nm}$ with a magnification of $30 \mathrm{k}$, the nanocomposite is in a cubic shape with soft edges and the rough corners of the cube are indicated by an orange arrow. The soft edges and rough corners of the cube are due to the product being calcined at $400{ }^{\circ} \mathrm{C}$. In Fig. 7(b), at $250 \mathrm{~nm}$ with a magnification of $30000 \times$, the surface of RGO can be seen, as indicated by the blue arrow. In Fig. 7(c), with a small range of $150 \mathrm{~nm}$ and Fig. 7 (d) with a small range of $100 \mathrm{~nm}$, small nanoparticles can be seen with a magnification power of $30000 \times$ and $40000 \times$, respectively. In the case of the metal oxide nanoparticles, the cubic particles show pores in their cube. These small pores can reduce the purity and the compatibility of the product and damage the surface area but in the tin cobalt oxide nanocomposite with RGO, the shape of the product is compact but irregular. The TEM images of the product confirm all the previous results of the SEM and XRD.

\section{Photocatalytic applications}

Removal of the color of Reactive Black 5 under sunlight and in the presence of the catalyst and hydrogen peroxide is shown in Fig. 8. The reduction of the RB 5 dye in the presence of the catalyst was investigated with the help of a UV-visible spectrophotometer because RB 5 azo dye strongly absorbs at $598 \mathrm{~nm}$. The degradation of the dye was checked in the absence of the nanocomposite, but the maximum absorbance at $598 \mathrm{~nm}$ stayed the same with time. This showed that the degradation of the RB 5 dye could not be possible in the absence of the nanocomposite. Thus, the photocatalytic degradation of the dye that was carried out in the presence of an excess amount of hydrogen peroxide and sun irradiation increased the degradation rate, such that the reduction of dye followed pseudo first order kinetics. The addition of hydrogen peroxide enhanced the degradation of the dye because of the additional generation of hydroxyl radicals and prevention of electron-hole pair recombination. ${ }^{57}$

\section{UV spectra of the composite and the band gap calculation}

The resulting UV spectrum obtained from the $\mathrm{C}_{16} \mathrm{Co}_{4} \mathrm{O}_{16} \mathrm{Sn}$ is shown in Fig. 9(a). The recorded spectral data showed a strong 
Table 2 Summary of parameters obtained from XRD analysis of product $\mathrm{C}_{16} \mathrm{CO}_{4} \mathrm{O}_{16} \mathrm{Sn}$

\begin{tabular}{ll}
\hline Parameters & Results \\
\hline Space group & $F-43 c$ \\
Space group number & 219 \\
Crystal system & Cubic \\
Cell parameters & \\
$A$ & \\
$B$ & $17.2550 \AA$ \\
$C$ & $17.2550 \AA$ \\
& $17.2550 \AA$ \\
$\alpha$ Angles & \\
$\beta$ & \\
$\gamma$ & $90^{\circ}$ \\
& $90^{\circ}$ \\
& $90^{\circ}$
\end{tabular}

Atomic coordinates

$x, y$ and $z$ coordinates of $\mathrm{Sn}$

$0.000,0.000$ and 0.000

$x, y$ and $z$ coordinates of Co

$x, y$ and $z$ coordinates of $\mathrm{O}$

$x, y$ and $z$ coordinates of $\mathrm{C}$

Calculated density

$I / I_{\text {cor }}$

2-Theta, $d$-spacing and miller indices $(h k l)$

$-0.193,0.043$ and

$-0.109$

$-0.151,-0.007$ and $-0.099$

$2.07500 \mathrm{~g} \mathrm{~cm}^{-3}$

5.800000

$15.621^{\circ}, 5.2026 \AA$

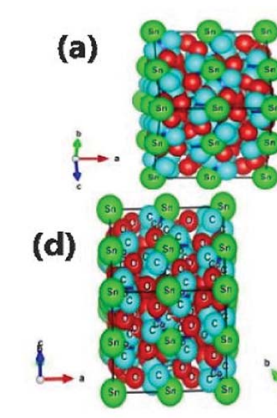

(b)

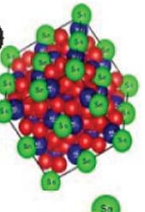

(e)

(c)

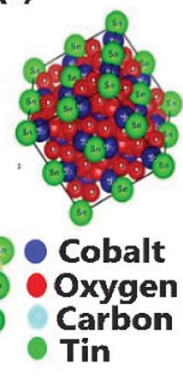

\section{(f)}

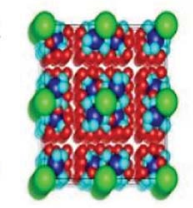

(g)

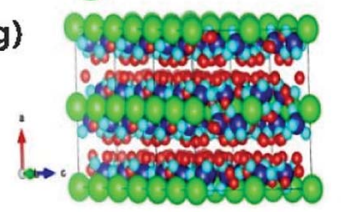

Fig. 3 The structural model of $\mathrm{C}_{16} \mathrm{CO}_{4} \mathrm{O}_{16} \mathrm{Sn}$ : (a) the position of the tin atoms in the cubic lattice. (b) The position of the tin and cobalt atoms in the cubic lattice with different orientations. (c and d) Description of the oxygen atoms (red) in the cube with more than one rotation of the cube. (e) Representation of all the atoms present in the cubic lattice. (f and g) The correct place for every atom present in the product at one or three cubic cells.

and (311)

$17.541^{\circ}, 4.9811 \AA$

and $(222)$

$25.453^{\circ}, 3.5222 \AA$

and (242)

$30.744^{\circ}, 2.9166 \AA$

and (513)

$33.241^{\circ}, 2.8758 \AA$

and (060)

$36.203^{\circ}, 2.4902 \AA$

and (444)

$45.443^{\circ}, 1.9924 \AA$

and (571)

$53.191^{\circ}, 1.6920 \AA$

and (682)

$63.961^{\circ}, 1.4635 \AA$

and (793)

$73.513^{\circ}, 1.3474 \AA$

and (868)

$75.793^{\circ}, 1.2897 \AA$

and (797)

light $)=3.0 \times 10^{8} \mathrm{~m} \mathrm{~s}^{-1}, \lambda$ (cut-off wavelength) $=4.1882 \times 10^{-9}$ $\mathrm{m}$, and $1 \mathrm{eV}=1.6 \times 10^{-19} \mathrm{~J}$ (conversion factor). The band gap is calculated to be $4.7418 \times 10^{-19} \mathrm{~J}$ or $2.9636 \mathrm{eV}$.

\section{Dye dependent UV-Vis spectra}

The dye concentration dependent UV-Vis spectra in the presence of $0.50 \mathrm{mg} \mathrm{ml}^{-1}$ of catalyst and $2 \mathrm{ml}$ of hydrogen peroxide is shown in Fig. 10.

These dye concentration dependent spectra were taken to study the maximum absorption and intensity of the dye in the absence of a catalyst and hydrogen peroxide. It can be seen in Fig. 10 that at $10 \mathrm{ppm}$ dye solution the maximum absorbance is 0.410 and with $20 \mathrm{ppm}$ dye solution the maximum absorption is 0.653 and similarly at concentration of $30 \mathrm{ppm}$ dye solution max absorption is shown at 0.973 . All the maximum absorptions were seen at $598 \mathrm{~nm}$. Thus, a dye with a maximum concentration was chosen for further study of different parameters of RB 5 dye degradation.

\section{Time dependent UV-Vis spectra}

in the percentage reflectance mode. The term band gap refer to the difference in energy between the conduction band at the bottom and the valence band at the top and is indicated by a double blue arrow in Fig. 9(b). Electrons have the capacity to move up from one band to another. The transition of electrons from the valence band to the conduction band requires minimum packets of energy. It can be seen from Fig. 9(b) that as the density of state increases, the band gap difference also increases. In the calculation of the band gap, the energy $(E)=$ $h c / \lambda$ where $h$ (Planck's constant $)=6.62 \times 10^{-34} \mathrm{~J} \mathrm{~s}, c($ speed of
The RB 5 dye degradation time dependent UV-visible spectra in the presence of $0.5 \mathrm{mg} \mathrm{ml}^{-1}$ of catalyst and $2 \mathrm{ml}$ of hydrogen peroxide under sun irradiation is shown in Fig. 11. It can be seen that when the process starts, the maximum absorbance at $598 \mathrm{~nm}$ is 0.973 but with the passage of time, absorbance at $598 \mathrm{~nm}$ decreases to 0.404 after $120 \mathrm{~min}$ of stirring under sunlight irradiation. This shows that the dye is degraded and the nanocomposite has a significant impact on dye degradation. 


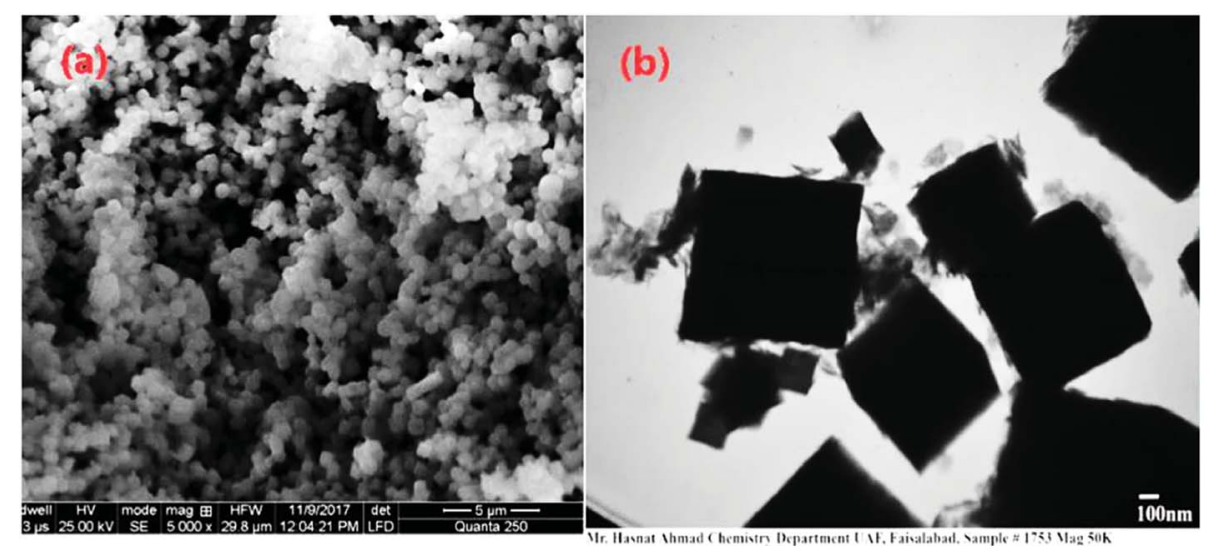

Fig. 4 (a) SEM and (b) TEM images of the simple tin cobalt oxide nanoparticles.

\section{Effect of catalyst concentration variation}

Fig. 12(a) shows the graph of the absorbance of dye versus time in the presence of $0.30,0.50$ and $0.70 \mathrm{mg} \mathrm{ml}^{-1}$ of catalyst and sunlight. It can be seen in the case of small dosages of catalyst that initially the change in value of absorbance with the passage of time is very small but as the dosage of catalyst increases, the rate of degradation is also increased. As the time passes, the process of dye degradation is increased and with the highest ratio of catalyst dosage i.e., $0.70 \mathrm{mg} \mathrm{ml}^{-1}$. At this dosage of catalyst the dye degraded with a quick time interval of $140 \mathrm{~min}$ and in the case of the other two dosages, the dye takes $160 \mathrm{~min}$ to degrade, which shows how the dosage of catalyst is important for the degradation of the RB 5 azo dye. In the case of 0.50 and
$0.30 \mathrm{mg} \mathrm{ml}^{-1}$ catalyst dosage, a rapid decrease in the value of absorbance with time is firstly observed and then this decrease in absorbance becomes slow as compared to the case of $0.70 \mathrm{mg}$. $\mathrm{ml}^{-1}$ catalyst dosage. The data from Fig. 12(a) is used to find the value of $k_{\text {app }}$. The plot of the catalyst dosage and $k_{\text {aap }}$ is shown in Fig. 12(b). The value of $k_{\text {aap }}$ increases from 0.003 to $0.059 \mathrm{mg}$ $\mathrm{ml}^{-1}$ by increasing the concentration of the catalyst from 0.30 to $0.50 \mathrm{mg} \mathrm{ml}^{-1}$. This increase in the value of $k_{\text {app }}$ is because of the increase in the number of available active sites with an increasing concentration of catalyst. This shows that at a low dosage of catalyst, the speed of catalysis is slow. In all the dye degradation processes where the dosage of catalyst varies with time, the other two parameters (dye concentration and hydrogen peroxide concentration) were constant.

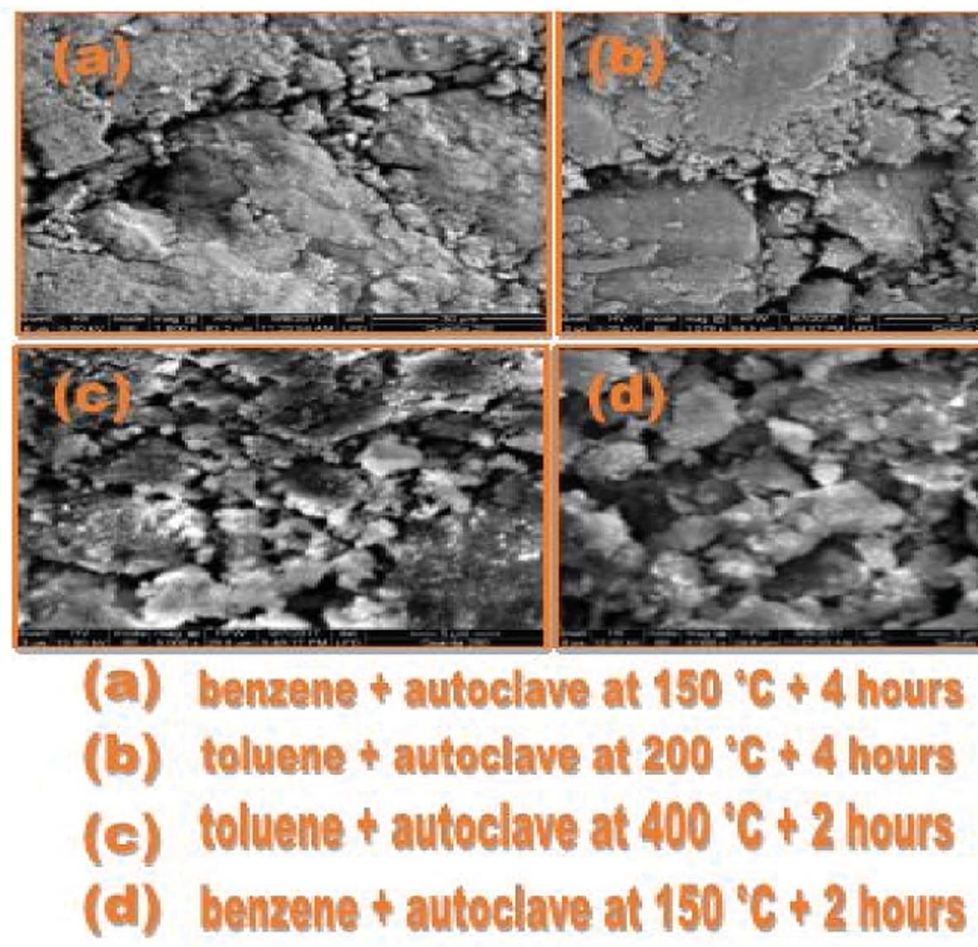

Fig. 5 (a) and (b) SEM images of the first attempt of the nanocomposite and (c) and (d) SEM images of the second attempt of the nanocomposite. 


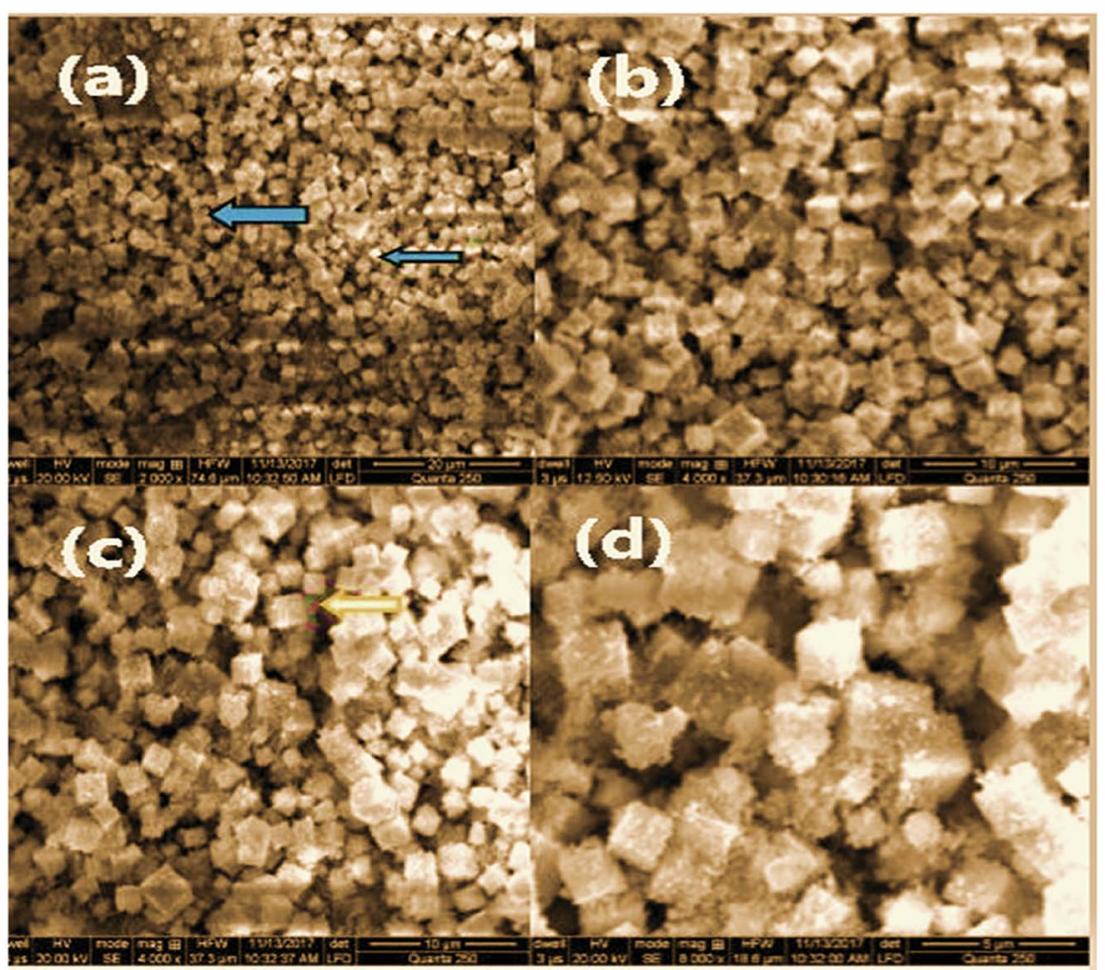

Fig. 6 SEM images of the newly synthesized nanocomposite.

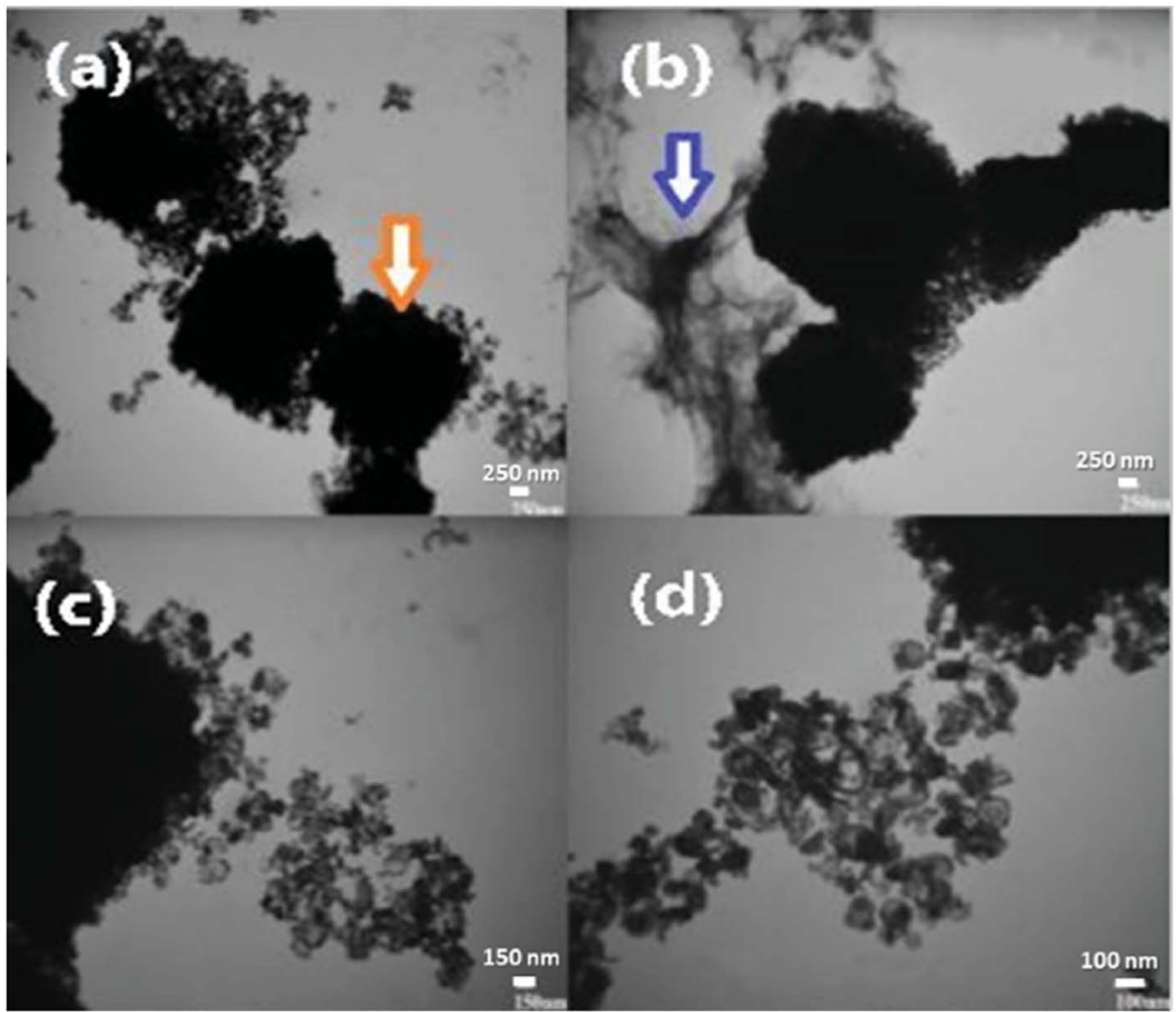

Fig. 7 TEM images of the synthesized GO based tin cobalt oxide nanocomposite at different magnifications. 


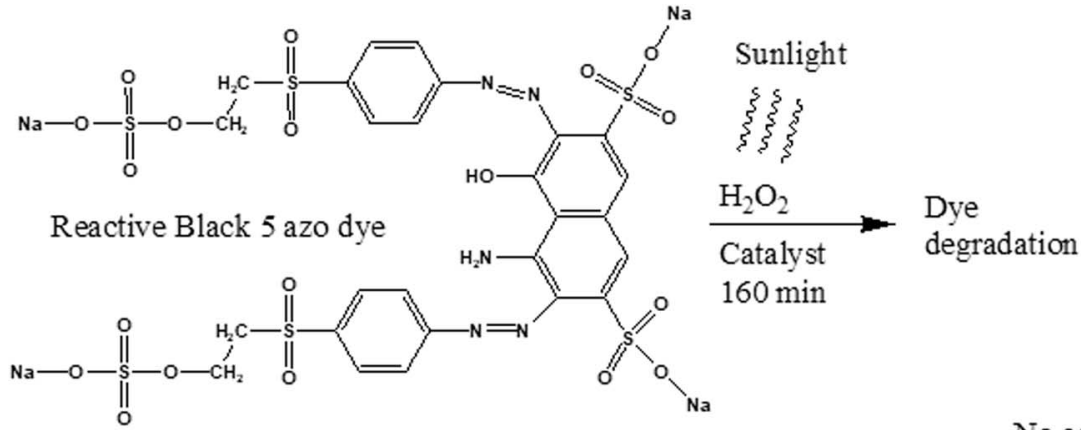

Black color

No color

Fig. 8 Removal of the color of Reactive Black 5 under sunlight and in the presence of a catalyst and hydrogen peroxide.
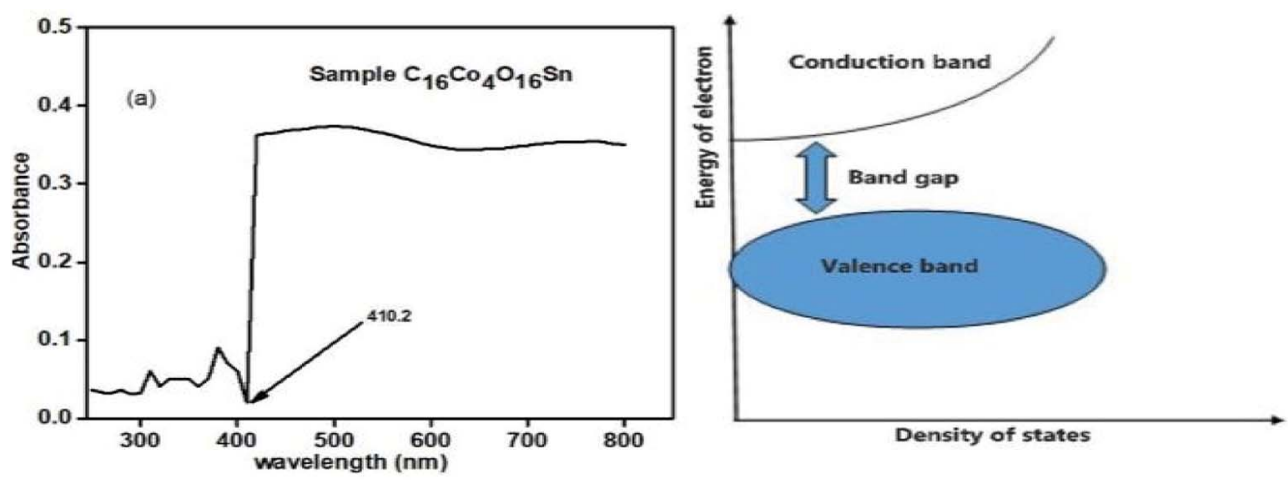

Fig. $9 \mathrm{UV} /$ visible spectra of the sample $\mathrm{C}_{16} \mathrm{CO}_{4} \mathrm{O}_{16} \mathrm{Sn}$ (left). Pictorial diagram of the explanation of band gap (right).

\section{Effect of hydrogen peroxide without a catalyst}

The graph of absorbance versus time for 1,2 and $3 \mathrm{ml}$ concentrations of hydrogen peroxide in the absence of a catalyst is shown in Fig. 13. In this graph, minor changes with fluctuating values of dye absorbance can be seen. At $20 \mathrm{ppm}$ concentration, the dye shows the lowest absorbance of 0.595 with $3 \mathrm{ml}$ of hydrogen peroxide amount and in the absence of a catalyst. This shows that the catalyst has a huge impact on the photocatalytic degradation.

\section{Effect of hydrogen peroxide concentration in the presence of a catalyst}

The graph of absorbance versus time for 1, 2 and $3 \mathrm{ml}$ concentration of hydrogen peroxide is shown in Fig. 14. The graph in Fig. 12 is like that of Fig. 14. In this plot, initially the absorbance does not decrease with time in the case of $1 \mathrm{ml}$ of hydrogen peroxide concentration. However, in the case of a $2 \mathrm{ml}$ concentration of hydrogen peroxide, the absorbance decreases throughout the time period and decreases until the start of the decolorization. However, as the amount of hydrogen peroxide increases to $3 \mathrm{ml}$, a sharp decrease in the absorbance can be seen and then in a short period of time the absorbance decreases slowly but at $80 \mathrm{~min}$ a sharp decrease can be seen and then a continuous decrease in absorbance is observed for $160 \mathrm{~min}$. The maximum decrease in absorbance can be seen in
$3 \mathrm{ml}$ of hydrogen peroxide at a 160 min time interval, which is 0.079 . After $160 \mathrm{~min}$, the photocatalytic dye degradation process stops and the dye solution shows almost the same absorbance as the full degradation of dye within 2 hours. In all the dye degradation processes where the hydrogen peroxide concentration varies, the other two parameters (dye concentration and catalyst dosage) are constant. The data from Fig. 14(a) is used to

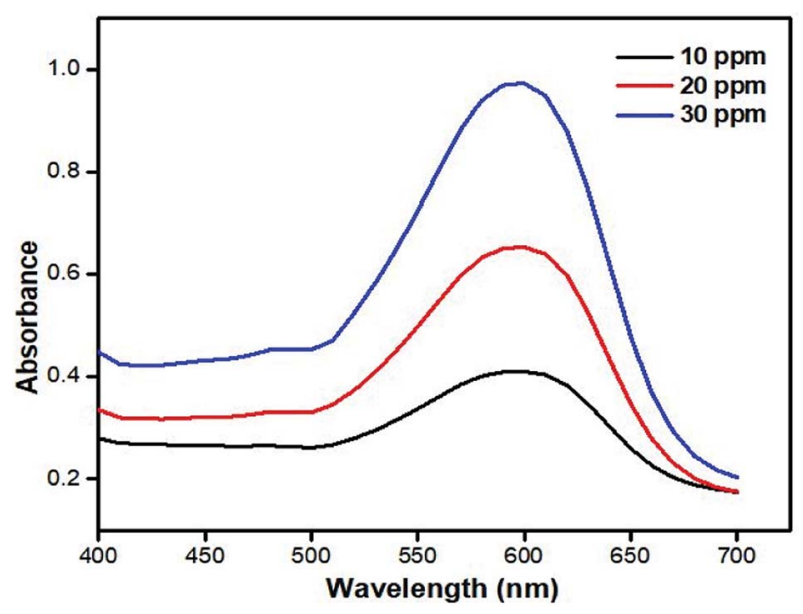

Fig. 10 Comparison of dye absorbance spectra at different concentrations of dye solution and at $0.50 \mathrm{mg} \mathrm{ml}^{-1}$ concentrations of catalyst and $2 \mathrm{ml}$ of hydrogen peroxide. 


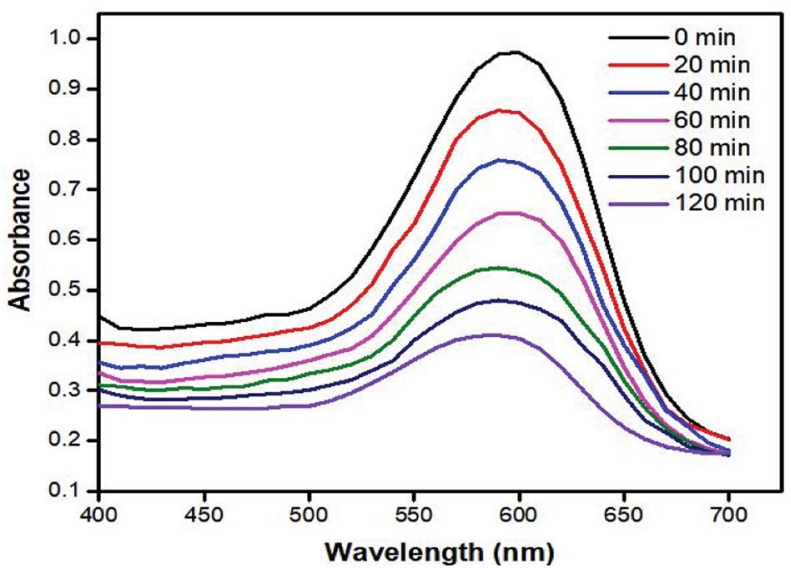

Fig. 11 UV-Vis spectra of the photocatalytic degradation of the dye at different time intervals under sunlight (conditions: [RB5] $=30 \mathrm{ppm}$, [hydrogen peroxide] $=2 \mathrm{ml}$, and [catalyst] $=0.50 \mathrm{mg} \mathrm{ml}^{-1}$ ).

find the value of $k_{\text {app }}$. The plot of catalyst dosage and $k_{\text {aap }}$ is shown in Fig. 14(b). The value of $k_{\text {aap }}$ is increased from 0.0019 to $0.0032 \mathrm{mg} \mathrm{ml}^{-1}$ by increasing the amount of hydrogen peroxide from 1 to $3 \mathrm{ml}$. This increase in the value of $k_{\text {app }}$ is because of the increase in the number of available active sites with increasing the concentration of catalyst.

\section{Mechanism of dye degradation}

Nano level semiconductors have a higher volume to surface area ratio than their bulk counterparts, which therefore allows a higher absorption of photons in the presence of a photocatalytic surface. Furthermore, recombining of $\mathrm{e}^{-}$and hole pairs in the semiconductor nanoparticles is reduced when particle size is smaller. When the size of particles in the semiconductor is reduced to the nanometer level, the energy band gap greatly increases, which leads to huge redox potentials in the whole system Therefore bulk scale semiconductors are expected to lower photocatalytic activity while nanoscale semiconductors have a high photocatalytic activity. ${ }^{58}$ Commonly, to

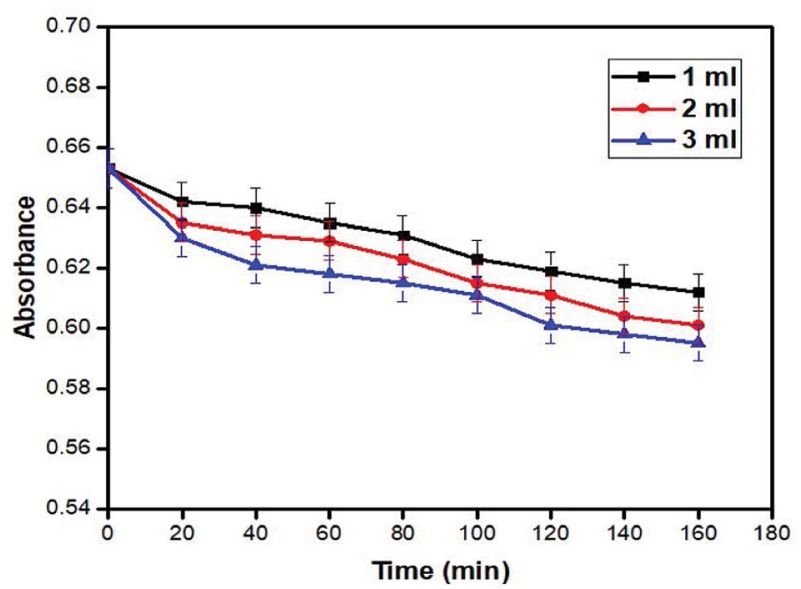

Fig. 13 Graph of time versus absorbance for the photocatalytic degradation of dye at different dosages of hydrogen peroxide (conditions: $[\mathrm{RB} 5]=20 \mathrm{ppm}$, [hydrogen peroxide] $=1,2$ and $3 \mathrm{ml}$, and [catalyst $]=$ absence of catalyst).

improve the efficiency of a catalyst, the number of electrons are reduced and the charge rate is enhanced so the recombination of holes and electrons is very important. It is known that semiconductor photocatalyzed reactions are started by holes or electrons being generated in the valence band or conduction band by semiconductor nanoparticles. ${ }^{59}$ After adding the catalyst into the solution, light is absorbed in the form of energy according to the band gaps. Positive holes in the VB are formed due to the transfer of electrons from the valence band to conduction band.

$$
\text { Semiconductor }+ \text { UV light } \rightarrow \mathrm{h}^{+}+\mathrm{e}^{-}
$$

An electron hole pair has a lifetime of only a few seconds but it is still enough to start a redox reaction with the semiconductor nanoparticles in the solution. There are three possible reaction pathways which have been proposed in the photochemical reaction (Fig. 15).
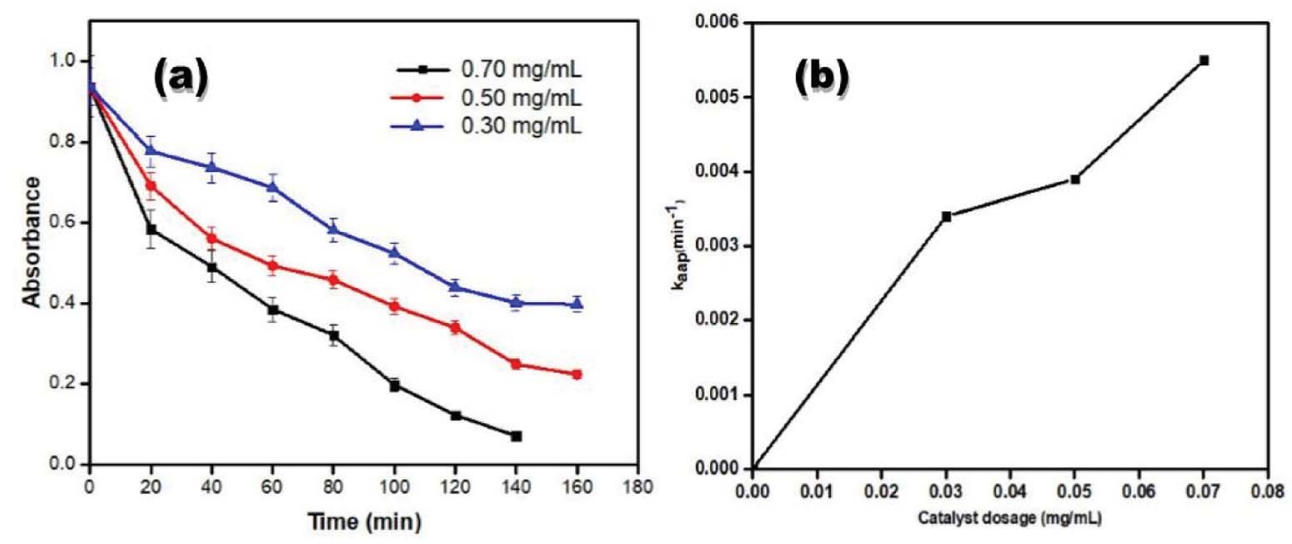

Fig. 12 (a) Graph of time versus absorbance for photocatalytic degradation of dye at different dosages of catalyst (conditions: [dye] = 30 ppm, [hydrogen peroxide] $=2 \mathrm{ml}$, [catalyst] $=0.30,0.50$ and $0.70 \mathrm{mg} \mathrm{ml}^{-1}$ ). (b) Plot of $k_{\text {app }}$ versus different concentrations of catalyst (conditions: [RB5] $=30 \mathrm{ppm}$, [hydrogen peroxide] $=2 \mathrm{ml}$, and [catalyst] $=0.30,0.50$ and $0.70 \mathrm{mg} \mathrm{ml}^{-1}$ ). 

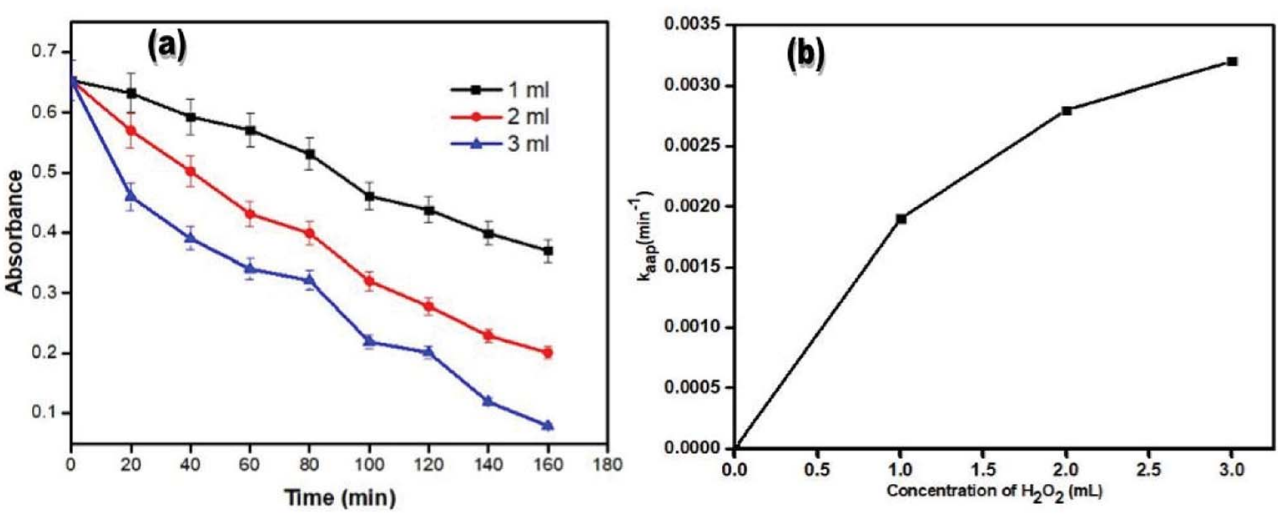

Fig. 14 (a) Graph of time versus absorbance for photocatalytic degradation of the dye at different dosages of hydrogen peroxide (conditions: [dye] $=30 \mathrm{ppm}$, [hydrogen peroxide] 1,2 and $3 \mathrm{ml}$, and [catalyst] $=0.50 \mathrm{mg} \mathrm{ml}^{-1}$ ). (b) Plot of $k_{\text {app }}$ versus different concentrations of hydrogen peroxide (conditions: [RB5] $=30 \mathrm{ppm}$, [hydrogen peroxide] $=1,2$ and $3 \mathrm{ml}$, and [catalyst] $=0.50 \mathrm{mg} \mathrm{ml}^{-1}$ ).

(1) An hydroxyl radical $(\mathrm{OH})$ is oxidized by water and a positive hole which further oxidizes the dye molecules.

$$
\mathrm{H}_{2} \mathrm{O}+\mathrm{h}^{+} \rightarrow \mathrm{OH}^{\cdot}+\mathrm{H}^{+}
$$

$\mathrm{OH} \cdot+\mathrm{RB} 5$ dye $\stackrel{-2 \mathrm{H}^{+}}{\longrightarrow}$ (product) oxidised dye molecules

(2) A super oxide anion is formed when dissolved oxygen is reduced by an electron and this anion will start the mineralization of the RB5 dye. This super oxide radical again reduces to hydrogen peroxide.

$$
\begin{gathered}
\mathrm{O}_{2}+\mathrm{e}^{-} \rightarrow \mathrm{O}_{2}^{-\cdot} \\
\mathrm{O}_{2}^{\cdot}+\mathrm{H}^{+} \rightarrow \mathrm{HO}_{2}^{-} \stackrel{\mathrm{HO}_{2}^{-}}{\longrightarrow} \mathrm{H}_{2} \mathrm{O}_{2}+\mathrm{O}_{2} \\
\mathrm{O}_{2}^{-}+\mathrm{HO}_{2}^{\cdot} \rightarrow \mathrm{HO}_{2}^{-}+\uparrow \mathrm{O}_{2} \stackrel{\mathrm{H}^{+}}{\longrightarrow} \mathrm{H}_{2} \mathrm{O}_{2}
\end{gathered}
$$

Cleavage of $\mathrm{H}_{2} \mathrm{O}_{2}$

$$
\begin{gathered}
\mathrm{H}_{2} \mathrm{O}_{2}+\mathrm{O}_{2}^{-\cdot} \rightarrow \mathrm{OH}^{\cdot}+\mathrm{O}_{2}+\mathrm{OH}^{-} \\
\mathrm{H}_{2} \mathrm{O}_{2} \rightarrow 2 \mathrm{OH}^{\cdot}
\end{gathered}
$$

(3) An hydroxyl radical $(\mathrm{OH})$ is produced by water molecules by a positive hole which causes in turn the oxidization of the dye molecules.

For the confirmation of this mechanism, the presence of hydrogen peroxide for degradation of the RB5 azo dye in the presence of sunlight was investigated. For this reason, $\mathrm{KMno}_{4}$ was added into the solution as a titrant. When it was added into the solution, the purple color was diminished and hydrogen peroxide was produced consistently throughout the photocatalytic decomposition of the RB5 dye in which the permanganate ion acts as an oxidizing agent and causes the oxidation of hydrogen peroxide. The permanganate ion was reduced from $\mathrm{a}+7$ oxidation state (purple color) to $\mathrm{a}+2$ oxidation state in $\mathrm{Mn}$ with no color. ${ }^{60,61}$

$$
\begin{gathered}
\mathrm{H}_{2} \mathrm{O}_{2} \rightarrow \mathrm{O}_{2}+2 \mathrm{H}^{+}+2 \mathrm{e}^{-} \\
\mathrm{MnO}_{4}{ }^{-}+5 \mathrm{e}^{-}+8 \mathrm{H}^{+} \rightarrow \mathrm{Mn}^{2+} \cdot 4 \mathrm{H}_{2} \mathrm{O}
\end{gathered}
$$

\section{$\mathrm{C}_{16} \mathrm{Co}_{4} \mathrm{O}_{16} \mathrm{Sn}$ nanoparticles as a catalyst for fuel efficiency}

Low octane kerosene oil was used in the presence of the synthesized nanocomposite as a reference for investigating the efficiency of this fuel and to study the properties of modified kerosene oil because kerosene oil is commonly used in heavy jet engines and aircraft. The efficiency of the fuel was monitored by examining all the parameters at different concentrations of fuel in the presence of the newly synthesized nanocomposite. The fire point, flash point, cloud point, pour point and calorific values were observed to examine the burning properties of pure kerosene oil as a model reaction. To analyze the physical characteristics of kerosene oil, the specific gravity was calculated.

\section{Effect of the $\mathrm{C}_{16} \mathrm{Co}_{4} \mathrm{O}_{16} \mathrm{Sn}$ nanocomposite on the efficiency of kerosene oil}

The effect of the synthesized nanocomposite on the efficiency of kerosene oil was investigated by different parameters such as fire point, flash point and specific gravity. These parameters were studied at various dosages of catalyst $(0,30,60$ and $90 \mathrm{mg}$ $\mathrm{ml}^{-1}$ ). All the results secured by using various dosages of catalyst were compared with reference to pure kerosene oil.

\section{Flash point and fire point}

The effects of flash point and fire point on the efficiency of pure kerosene oil at different concentrations of nanocomposite $(0$, 30, 60 and 90 ppm) are shown in Fig. 16 and 17. 


\section{Proposed reactive black 5 azo dye degradation pathways}

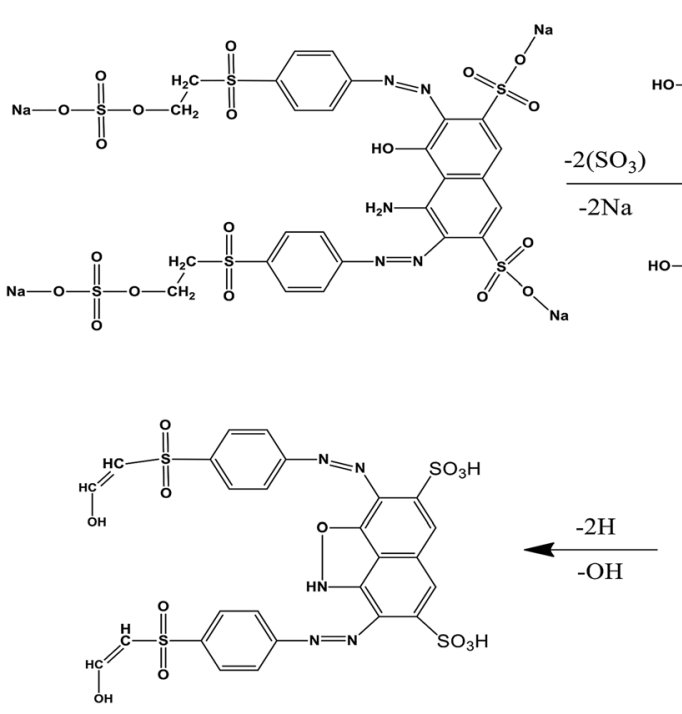

Product 1
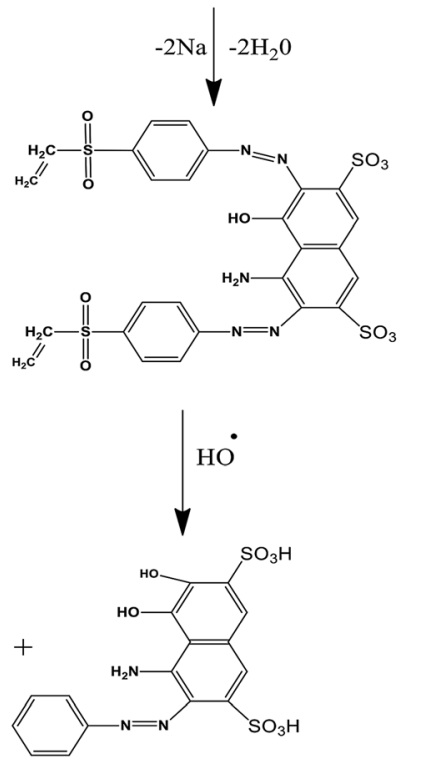

Product 2

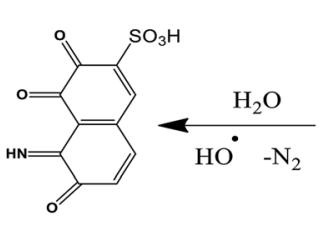

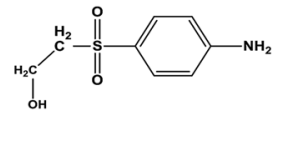

Intermediate state

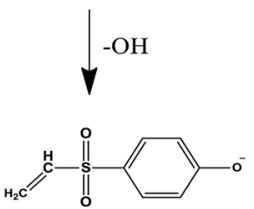

Product 3

Fig. 15 Proposed degradation routes for the photocatalytic oxidation of the Reactive Black 5 dye.

It can be clearly seen from the plots that without the nanocomposite, the flash point and fire point temperature of pure kerosene oil is high. But after some time, as the concentration of nanocatalyst increases, the flash and fire point temperature significantly decreases. The decreasing plot shows the continuous decrease in the flash and fire point temperature. This decreasing pattern of the flash and fire point temperatures shows that the newly synthesized nanocomposite has the best characteristics as a catalyst to increase the efficiency of pure kerosene oil.

From Table 3, it can be clearly seen that the temperature of the flash and fire point of pure kerosene oil was high in the absence of the nanocatalyst. These values sharply decrease initially but by increasing the concentration of nanoparticles these values gradually decrease until the end of the $90 \mathrm{ppm}$ concentration of kerosene oil. The temperature difference between the flash and fire points of pure kerosene oil was $7{ }^{\circ} \mathrm{C}$ and after adding the nanocatalyst, initially it changed to $6{ }^{\circ} \mathrm{C}$ and ended with $5{ }^{\circ} \mathrm{C}$. This difference in temperature indicates

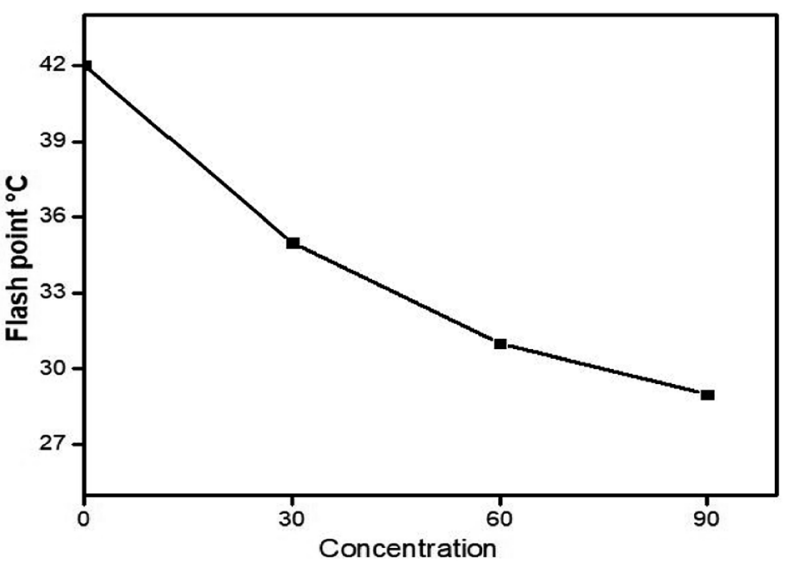

Fig. 16 Effect of the $\mathrm{C}_{16} \mathrm{Co}_{4} \mathrm{O}_{16} \mathrm{Sn}$ nanocomposite on the flash point of pure kerosene oil. 


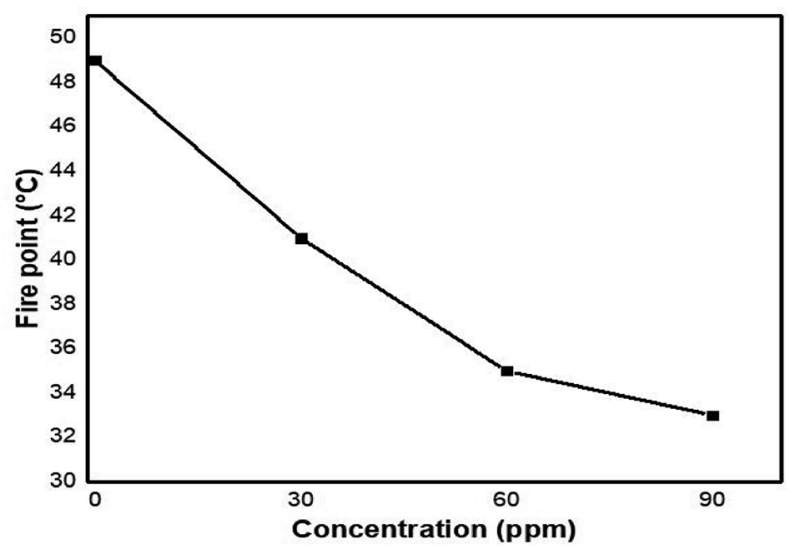

Fig. 17 Effect of the $\mathrm{C}_{16} \mathrm{Co}_{4} \mathrm{O}_{16} \mathrm{Sn}$ nanocomposite towards the fire point of pure kerosene oil.

that the new nanocomposite plays a vital role as a catalyst to increase the efficiency of pure kerosene oil by varying the dosage of the catalyst at commercial as well as for analytical scale.

\section{Specific gravity}

The specific gravity of pure kerosene oil was examined by a specific gravity meter (DA640) with 10 seconds of pump timing for each sample of the $\mathrm{C}_{16} \mathrm{Co}_{4} \mathrm{O}_{16} \mathrm{Sn}$ nanocatalyst at $25^{\circ} \mathrm{C}$ being used to check the effect of the specific gravity on pure kerosene oil.

Firstly, the specific gravity of kerosene oil in the absence of the nanocatalyst at $20^{\circ} \mathrm{C}$ was measured which gave low values of specific gravity $0.7853 \mathrm{~g} \mathrm{~cm}^{-3}$. When the nanocatalyst at $30 \mathrm{ppm}$ concentration was added into the pure kerosene oil it showed some increasing behavior i.e. the specific gravity of the pure kerosene oil increased to $0.7878 \mathrm{~g} \mathrm{~cm}^{-3}$ and was continuously increased by enhancing the concentration of the nanocatalyst. A higher concentration of nanoparticles dosage (90 ppm) shows the high values of specific gravity. The high specific gravity of kerosene oil was due to the high surface area of the newly synthesized nanoparticles. The effect of the nanoparticles on the specific gravity of the fuel is shown in Fig. 18. By running the sample on (SGM) three times, the results show that the specific gravity value of pure kerosene oil is low as compared to the modified kerosene oil. At different concentrations, the specific gravity values shift but they are lower than the pure sample.

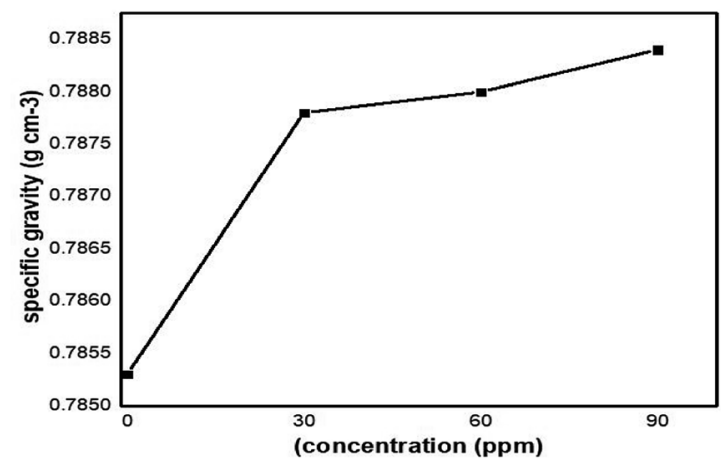

Fig. 18 Effect of the $\mathrm{C}_{16} \mathrm{Co}_{4} \mathrm{O}_{16} \mathrm{Sn}$ nanoparticles on the specific gravity of kerosene oil.

\section{Pour point and cloud point}

The pour point and cloud point values of pure kerosene oil were high in the absence of the nanocatalyst. The values of cloud point at the start decreased by the addition of nanoparticles. With a high dosage of the catalyst, the cloud point values of the pure kerosene oil initially decreased by $1{ }^{\circ} \mathrm{C}$ per $30 \mathrm{ppm}$ and ended with $3{ }^{\circ} \mathrm{C}$ per $30 \mathrm{ppm}$ approximately. In the case of the pour point, the temperature in the presence of three different concentrations of the nanocatalyst in pure kerosene oil was found to be in the range of -15 to $-33^{\circ} \mathrm{C}$. The pour point temperature constantly decreased by $1{ }^{\circ} \mathrm{C}$ for each concentration of kerosene oil by increasing the amount of $\mathrm{C}_{16} \mathrm{Co}_{4} \mathrm{O}_{16} \mathrm{Sn}$ nanoparticles up to $90 \mathrm{ppm}$. These values show that the pour point temperature is not affected by adding different dosages of nanocatalyst.

\section{Calorimetric values}

In the presence of three different dosages of the concentration of $\mathrm{C}_{16} \mathrm{Co}_{4} \mathrm{O}_{16} \mathrm{Sn}$ nanoparticles (30, 60 and $90 \mathrm{ppm}$ ), the calorific values of pure kerosene oil are given in Table 3 . It can be clearly seen from the given table that pure kerosene oil in the absence of a catalyst shows a low calorific value. After adding a catalyst of three different concentrations, the kerosene oil shows constantly high calorific values by adding a high concentration dosage of nanoparticles.

\section{Conclusions}

A composite of cobalt tin oxide nanoparticles with RGO was successfully synthesized by a solvothermal approach. The newly

Table 3 Effect of the nanocomposite on the various parameters and different concentrations of kerosene oil

\begin{tabular}{|c|c|c|c|c|}
\hline \multirow[b]{2}{*}{ Parameters } & \multicolumn{4}{|c|}{ Concentration of catalyst dosage } \\
\hline & (Pure kerosene oil) & $30 \mathrm{ppm}$ & $60 \mathrm{ppm}$ & $90 \mathrm{ppm}$ \\
\hline Flash point & $42{ }^{\circ} \mathrm{C}$ & $35{ }^{\circ} \mathrm{C}$ & $31{ }^{\circ} \mathrm{C}$ & $29{ }^{\circ} \mathrm{C}$ \\
\hline Fire point & $49{ }^{\circ} \mathrm{C}$ & $41{ }^{\circ} \mathrm{C}$ & $35{ }^{\circ} \mathrm{C}$ & $33{ }^{\circ} \mathrm{C}$ \\
\hline Specific gravity & $0.7853 \mathrm{~g} \mathrm{~cm}^{-3}$ & $0.7878 \mathrm{~g} \mathrm{~cm}^{-3}$ & $0.7880 \mathrm{~g} \mathrm{~cm}^{-3}$ & $0.7884 \mathrm{~g} \mathrm{~cm}^{-3}$ \\
\hline Cloud point & $9{ }^{\circ} \mathrm{C}$ & $6^{\circ} \mathrm{C}$ & $5{ }^{\circ} \mathrm{C}$ & $3{ }^{\circ} \mathrm{C}$ \\
\hline Pour point & $-15^{\circ} \mathrm{C}$ & $-19^{\circ} \mathrm{C}$ & $-22{ }^{\circ} \mathrm{C}$ & $-30{ }^{\circ} \mathrm{C}$ \\
\hline Calorific values & $920 \mathrm{~J} \mathrm{~g}^{-1}$ & $12604 \mathrm{~J} \mathrm{~g}^{-1}$ & $20819 \mathrm{~J} \mathrm{~g}^{-1}$ & $31412 \mathrm{~J} \mathrm{~g}^{-1}$ \\
\hline
\end{tabular}


synthesized nanocomposite was characterized by UV-visible spectroscopic analysis, EDX, XRD, SEM, TEM and X-ray diffraction (XRD). The investigation report confirms that the product is pure and the cobalt tin oxide nanoparticles are adsorbed over the surface of RGO. Controlled morphological experiments show that in the product, the nanocomposites are completely separate from each other and the sizes of the nanocomposite are in the nano range. The wavelength of the maximum absorption of the RB 5 azo dye is found to be $598 \mathrm{~nm}$. The degradation of the Reactive Black RB 5 azo dye was investigated to examine the photocatalytic properties of the newly synthesized nanocomposite. It was observed that the absorbance decreases in the presence of sunlight from 0.973 to 0.404 with an increase in the $\mathrm{C}_{16} \mathrm{Co}_{4} \mathrm{O}_{16} \mathrm{Sn}$ dosage from 0.30 to $0.70 \mathrm{mg} \mathrm{ml}^{-1}$. It is noted that the value of the absorbance is also decreased from 0.973 to 0.079 by increasing the amount of hydrogen peroxide from $1 \mathrm{ml}$ to $3 \mathrm{ml}$. The maximum degradation of Reactive Black 5 dye is observed for a $3 \mathrm{ml}$ concentration of hydrogen peroxide and $0.70 \mathrm{mg} \mathrm{ml} \mathrm{ml}^{-1}$ of catalyst. The synthesized nanocomposite was also used to examine the efficiency of kerosene oil by investigating different parameters of the modified kerosene oil. From the addition of the nanocomposite to pure kerosene oil, the calorific values were also increased which shows the effectiveness of the catalytic properties of the newly synthesized nanocomposite. It was also determined that the flash and fire point temperatures were significantly decreased by the addition of the $\mathrm{C}_{16} \mathrm{Co}_{4} \mathrm{O}_{16} \mathrm{Sn}$ nanoparticles. It is also observed that the $\mathrm{C}_{16} \mathrm{Co}_{4} \mathrm{O}_{16} \mathrm{Sn}$ nanoparticles have a positive effect on the pour point and cloud point temperatures of pure kerosene oil. The experimental results of photocatalytic and fuel additive applications indicate that the newly synthesized $\mathrm{C}_{16} \mathrm{Co}_{4} \mathrm{O}_{16} \mathrm{Sn}$ nanoparticles have an efficient surface area and photocatalytic properties.

\section{Conflicts of interest}

There are no conflicts to declare.

\section{Acknowledgements}

The authors would like to acknowledge the financial support provided by the Department of Chemistry, University of Agriculture, Faisalabad, Pakistan and Department of Chemistry, University of Sargodha, Sargodha, Pakistan. The paper was submitted by the corresponding author from King Fahd University of Petroleum and Minerals (KFUPM), Kingdom of Saudi Arabia.

\section{References}

1 A. R. Babar, et al., Electrical and dielectric properties of coprecipitated nanocrystalline tin oxide, J. Alloys Compd., 2010, 505(2), 743-749.

2 M. U. Niemann, et al., Processing analysis of the ternary $\mathrm{LiNH}_{2}-\mathrm{MgH}_{2}-\mathrm{LiBH}_{4}$ system for hydrogen storage, Int. J. Hydrogen Energy, 2009, 34(19), 8086-8093.
3 A. Chen and S. Chatterjee, Nanomaterials based electrochemical sensors for biomedical applications, Chem. Soc. Rev., 2013, 42(12), 5425-5438.

4 S. Jamil, et al., Synthesis, characterization and catalytic application of polyhedron zinc oxide microparticles, Mater. Res. Express, 2017, 4(1), 015902.

5 M. Mahmoudi, et al., Superparamagnetic iron oxide nanoparticles (SPIONs): development, surface modification and applications in chemotherapy, Adv. Drug Delivery Rev., 2011, 63(1-2), 24-46.

6 S. Jamil, M. R. S. A. Janjua and T. Ahmad, The synthesis of flower shaped microstructures of $\mathrm{Co}_{3} \mathrm{O}_{4}$ by solvothermal approach and investigation of its catalytic activity, Solid State Sci., 2014, 36, 73-79.

7 P. V. L. Reddy, et al., Photocatalytic degradation of bisphenol A in aqueous media: a review, J. Environ. Manage., 2018, 213, 189-205.

8 R. Mariappan and S. Mahalingam, [Bmim][TfO] ionic liquidassisted oriented growth of $\mathrm{Co}_{3} \mathrm{O}_{4}$ nanoworms, Mater. Res. Bull., 2013, 48(2), 618-623.

9 S. Farhadi, K. Pourzare and S. Sadeghinejad, Simple preparation of ferromagnetic $\mathrm{Co}_{3} \mathrm{O}_{4}$ nanoparticles by thermal dissociation of the $\left[\mathrm{Co}\right.$ II $\left.\left(\mathrm{NH}_{3}\right)_{6}\right]\left(\mathrm{NO}_{3}\right)_{2}$ complex at low temperature, J. Nanostruct. Chem., 2013, 3(1), 16.

10 L. Jiang, et al., Size-controllable synthesis of monodispersed $\mathrm{SnO}_{2}$ nanoparticles and application in electrocatalysts, $J$. Phys. Chem. B, 2005, 109(18), 8774-8778.

11 P. V. Viet, et al., Fusarium antifungal activities of copper nanoparticles synthesized by a chemical reduction method, J. Nanomater., 2016, 2016, 6.

12 M. U. Khalid, S. R. Khan and S. Jamil, Morphologically Controlled Synthesis of Cubes like Tin Oxide Nanoparticles and Study of its Application as Photocatalyst for Congo Red Degradation and as Fuel Additive, J. Inorg. Organomet. Polym. Mater., 2018, 28(1), 168-176.

13 A. Salimi, et al., Nanomolar detection of hydrogen peroxide on glassy carbon electrode modified with electrodeposited cobalt oxide nanoparticles, Anal. Chim. Acta, 2007, 594(1), 24-31.

$14 \mathrm{~S}$. Jamil, et al., The synthesis of porous $\mathrm{Co}_{3} \mathrm{O}_{4}$ micro cuboid structures by solvothermal approach and investigation of its gas sensing properties and catalytic activity, Mater. Res. Bull., 2013, 48(11), 4513-4520.

$15 \mathrm{~J}$. Zhu, et al., Supported cobalt oxide nanoparticles as catalyst for aerobic oxidation of alcohols in liquid phase, ACS Catal., 2011, 1(4), 342-347.

$16 \mathrm{X}$. J. Zhu, et al., Highly porous reticular tin-cobalt oxide composite thin film anodes for lithium ion batteries, $J$. Mater. Chem., 2009, 19(44), 8360-8365.

17 H. Jena, K. G. Kutty and T. Kutty, Ionic transport and structural investigations on $\mathrm{MSn}(\mathrm{OH})_{6}(\mathrm{M}=\mathrm{Ba}, \mathrm{Ca}, \mathrm{Mg}$, $\mathrm{Co}, \mathrm{Zn}, \mathrm{Fe}, \mathrm{Mn}$ ) hydroxide perovskites synthesized by wet sonochemical methods, Mater. Chem. Phys., 2004, 88(1), 167-179.

18 D. Huang, et al., Hydrothermal synthesis of $\mathrm{MSn}(\mathrm{OH})_{6}(\mathrm{M}=$ $\mathrm{Co}, \mathrm{Cu}, \mathrm{Fe}, \mathrm{Mg}, \mathrm{Mn}, \mathrm{Zn}$ ) and their photocatalytic activity for 
the destruction of gaseous benzene, Chem. Eng. J., 2015, 269, 168-179.

19 F. Huang, et al., A novel tin-based nanocomposite oxide as negative-electrode materials for Li-ion batteries, Mater. Lett., 2003, 57(22-23), 3341-3345.

$20 \mathrm{~F}$. Song, K. Schenk and X. Hu, A nanoporous oxygen evolution catalyst synthesized by selective electrochemical etching of perovskite hydroxide $\operatorname{CoSn}(\mathrm{OH})_{6}$ nanocubes, Energy Environ. Sci., 2016, 9(2), 473-477.

21 C. Y. Teh, T. Y. Wu and J. C. Juan, An application of ultrasound technology in synthesis of titania-based photocatalyst for degrading pollutant, Chem. Eng. J., 2017, 317, 586-612.

22 K. P. Loh, et al., Graphene oxide as a chemically tunable platform for optical applications, Nat. Chem., 2010, 2(12), 1015.

23 P. Avouris and F. Xia, Graphene applications in electronics and photonics, MRS Bull., 2012, 37(12), 1225-1234.

24 L. Lancellotti, et al., Graphene applications in Schottky barrier solar cells, Thin Solid Films, 2012, 522, 390-394.

$25 \mathrm{X}$. Huang, et al., Graphene oxide dielectric permittivity at $\mathrm{GHz}$ and its applications for wireless humidity sensing, Sci. Rep., 2018, 8(1), 43.

$26 \mathrm{~W}$. Subramonian and T. Y. Wu, Effect of enhancers and inhibitors on photocatalytic sunlight treatment of methylene blue, Water, Air, Soil Pollut., 2014, 225(4), 1922.

$27 \mathrm{~S}$. Li, et al., Facile synthesis of bimetallic $\mathrm{Ag}-\mathrm{Cu}$ nanoparticles for colorimetric detection of mercury ion and catalysis, Sens. Actuators, B, 2018, 255, 1471-1481.

28 P. Cheng, et al., Fast sonochemical synthesis of $\operatorname{CoSn}(\mathrm{OH})_{6}$ nanocubes, conversion towards shape-preserved $\mathrm{SnO}_{2}-$ $\mathrm{Co}_{3} \mathrm{O}_{4}$ hybrids and their photodegradation properties, Mater. Lett., 2013, 90, 19-22.

29 A. Vázquez-Olmos, et al., Mechanochemical Synthesis of $\mathrm{YFeO}_{3}$ Nanoparticles: Optical and Electrical Properties of Thin Films, J. Cluster Sci., 2018, 29(2), 225-233.

30 G. Sun, et al., Solvothermal synthesis and characterization of porous zinc hydroxystannate microspheres, Mater. Lett., 2015, 150, 105-107.

31 F. C. F. Low, et al., Investigation into photocatalytic decolorisation of CI Reactive Black 5 using titanium dioxide nanopowder, Color. Technol., 2012, 128(1), 44-50.

32 Z. Wang, et al., Amorphous $\mathrm{CoSnO}_{3} @ \mathrm{C}$ nanoboxes with superior lithium storage capability, Energy Environ. Sci., 2013, 6(1), 87-91.

$33 \mathrm{~J}$. Zhang, et al., Synthesis of $\mathrm{Co}_{2} \mathrm{SnO}_{4}$ hollow cubes encapsulated in graphene as high capacity anode materials for lithium-ion batteries, J. Mater. Chem. A, 2014, 2(8), 2728-2734.

34 Y.-h. Si, et al., Enhanced Visible Light Driven Photocatalytic Behavior of $\mathrm{BiFeO}_{3} /$ Reduced Graphene Oxide Composites, Nanomaterials, 2018, 8(7), 526.

35 L. Jiang, et al., Controlled synthesis of $\mathrm{CeO}_{2} /$ graphene nanocomposites with highly enhanced optical and catalytic properties, J. Phys. Chem. C, 2012, 116(21), 11741-11745.

36 J.-W. Shi, et al., The composite of nitrogen-doped anatase titania plates with exposed $\left\{\begin{array}{lll}0 & 0 & 1\end{array}\right\}$ facets/graphene nanosheets for enhanced visible-light photocatalytic activity, J. Colloid Interface Sci., 2014, 430, 100-107.

$37 \mathrm{Y}$. Cao, et al., Facile synthesis of $\mathrm{CoSnO}_{3} /$ Graphene nanohybrid with superior lithium storage capability, Electrochim. Acta, 2014, 132, 483-489.

38 M. Ismail, et al., Green synthesis of plant supported $\mathrm{Cu} \mathrm{Ag}$ and $\mathrm{Cu} \mathrm{Ni}$ bimetallic nanoparticles in the reduction of nitrophenols and organic dyes for water treatment, J. Mol. Liq., 2018, 260, 78-91.

$39 \mathrm{~J}$. Wang, et al., Iron-copper bimetallic nanoparticles supported on hollow mesoporous silica spheres: an effective heterogeneous fenton catalyst for orange II degradation, RSC Adv., 2015, 5(85), 69593-69605.

40 N. Qin, et al., Enhanced removal of trace Cr (VI) from neutral and alkaline aqueous solution by FeCo bimetallic nanoparticles, J. Colloid Interface Sci., 2016, 472, 8-15.

$41 \mathrm{Z}$. Guo, et al., Construction of cost-effective bimetallic nanoparticles on titanium carbides as a superb catalyst for promoting hydrolysis of ammonia borane, RSC Adv., 2018, 8(2), 843-847.

42 N. Arora, et al., 4-Nitrophenol reduction catalysed by Au-Ag bimetallic nanoparticles supported on LDH: homogeneous vs. heterogeneous catalysis, Appl. Clay Sci., 2018, 151, 1-9.

43 M. Khan, et al., Graphene based metal and metal oxide nanocomposites: synthesis, properties and their applications, J. Mater. Chem. A, 2015, 3(37), 18753-18808.

44 D. Mantzavinos and E. Psillakis, Enhancement of biodegradability of industrial wastewaters by chemical oxidation pre-treatment, J. Chem. Technol. Biotechnol., 2004, 79(5), 431-454.

45 S. Meriç, D. Kaptan and T. Ölmez, Color and COD removal from wastewater containing Reactive Black 5 using Fenton's oxidation process, Chemosphere, 2004, 54(3), 435441.

46 I. Poulios and I. Tsachpinis, Photodegradation of the textile dye Reactive Black 5 in the presence of semiconducting oxides, J. Chem. Technol. Biotechnol., 1999, 74(4), 349-357.

47 C. Tang and V. Chen, The photocatalytic degradation of reactive black 5 using $\mathrm{TiO}_{2} / \mathrm{UV}$ in an annular photoreactor, Water Res., 2004, 38(11), 2775-2781.

48 E. M. Samsudin, et al., Enhancement of the intrinsic photocatalytic activity of $\mathrm{TiO}_{2}$ in the degradation of 1,3,5triazine herbicides by doping with N, F, Chem. Eng. J., 2015, 280, 330-343.

49 M. Cao, et al., Photocatalytic degradation of tetrabromobisphenol A by a magnetically separable graphene- $\mathrm{TiO}_{2}$ composite photocatalyst: Mechanism and intermediates analysis, Chem. Eng. J., 2015, 264, 113-124.

50 R. Karthik, et al., A study of electrocatalytic and photocatalytic activity of cerium molybdate nanocubes decorated graphene oxide for the sensing and degradation of antibiotic drug chloramphenicol, ACS Appl. Mater. Interfaces, 2017, 9(7), 6547-6559.

51 A. Al Nafiey, et al., Reduced graphene oxide decorated with $\mathrm{Co}_{3} \mathrm{O}_{4}$ nanoparticles $\left(\mathrm{rGO}^{-} \mathrm{Co}_{3} \mathrm{O}_{4}\right)$ nanocomposite: a reusable catalyst for highly efficient reduction of 4- 
nitrophenol, and $\mathrm{Cr}(\mathrm{VI})$ and dye removal from aqueous solutions, Chem. Eng. J., 2017, 322, 375-384.

52 S. B. Jadhav and R. S. Singhal, Polysaccharide conjugated laccase for the dye decolorization and reusability of effluent in textile industry, Int. Biodeterior. Biodegrad., 2013, 85, 271-277.

53 C. Hessel, et al., Guidelines and legislation for dye house effluents, J. Environ. Manage., 2007, 83(2), 171-180.

54 C. Pratum, et al., Decolorization of reactive dyes and textile dyeing effluent by Pleurotus sajor-caju, 2012.

55 M. C. Silva, et al., Decolorization of the phthalocyanine dye reactive blue 21 by turnip peroxidase and assessment of its oxidation products, J. Mol. Catal. B: Enzym., 2012, 77, 9-14.

56 S. Jamil, et al., First Synthetic Study of Cube-Like Cobalt Hydroxystannate Nanoparticles as Photocatalyst for Drimarene Red K-4BL Degradation and Fuel Additive, $J$. Cluster Sci., 2018, 29, 685-696.
57 W. Subramonian, T. Y. Wu and S.-P. Chai, Photocatalytic degradation of industrial pulp and paper mill effluent using synthesized magnetic $\mathrm{Fe}_{2} \mathrm{O}_{3}-\mathrm{TiO}_{2}$ : treatment efficiency and characterizations of reused photocatalyst, $J$. Environ. Manage., 2017, 187, 298-310.

58 M. Sharma, et al., Photocatalytic degradation of organic dyes under UV-visible light using capped ZnS nanoparticles, Sol. Energy, 2012, 86(1), 626-633.

59 G. Zhou and J. Deng, Preparation and photocatalytic performance of $\mathrm{Ag} / \mathrm{ZnO}$ nano-composites, Mater. Sci. Semicond. Process., 2007, 10(2-3), 90-96.

60 A. N. Rao, B. Sivasankar, and V. Sadasivam, Photo-oxidative degradation of an azo dye direct red 31 in the presence of ZnS catalyst, 2010.

61 E. K. Goharshadi, et al., Photocatalytic degradation of reactive black 5 azo dye by zinc sulfide quantum dots prepared by a sonochemical method, Mater. Sci. Semicond. Process., 2013, 16(4), 1109-1116. 